British Journal of Chinese Studies, Vol. 9 (2), July 2019

ISSN 2048-0601

(C) British Association for Chinese Studies

\title{
Aestheticism versus Utilitarianism: The Reception of the "Tragic" in 1930s Chinese Literary Discourse
}

\author{
Tian GU \\ Nankai University
}

\begin{abstract}
This study examines the construction of the Chinese literary discourse on tragedy in the 1930s, when the intertwining connections between literature and politics left a noticeable influence on the Chinese understanding of the concept. It approaches the subject from three angles: first, it reviews both theoretical discussions of the concept of tragedy and the literary practice of the tragic, exploring possible factors that have either promoted or prevented the application of theory to practice. Second, it traces the changing relationship between pragmatic and aesthetic perspectives during the formation of the Chinese intellectual discourse on tragedy, analysing its relevance to the inextricable link between literature and politics in the 1930s. Thirdly, it investigates the differences between the Chinese perception of tragedy and its foreign origins, presenting the constant interplay among several cultural, social, and political elements that affected the establishment of the 1930s Chinese tragic tradition. In doing so, this study demonstrates the particular features of the Chinese perception of the tragic in the 1930s, as well as the decisive role that socio-political factors played in manipulating the intellectual practices at the time.
\end{abstract}

Keywords: the tragic, the 1930s Chinese literary field, theory and practice, aesthetics, pragmatic, utilitarian, literary realist.

The Chinese appropriation of the term "tragedy" (beiju) dates back to the beginning of the 20th century, when a pronounced influx of Western theories and concepts began to satisfy the appetite of a new generation of Chinese intellectuals, helping them to redefine their literary tradition in the wider context of world literature. Modern Chinese literary discourse on tragedy takes its shape from a pressing cultural and social crisis besetting the Chinese at the 
turn of the 20th century. The political imperative brought about by a series of military and diplomatic defeats against Western forces urged modern Chinese intellectuals to reflect upon the backwardness of Chinese culture and social institutions. As a result, literature has since then stood at the forefront of the campaign for an overall cultural and social revolution, and shouldered the compelling obligation to eradicate the "chronic disease" produced by old traditions that lasted for more than two thousand years, in order to "establish for Chinese politics a foundation for reformation at the artistic and literary level" (Hu, 1922: 4). Therefore, in the modern Chinese notion of tragedy, it is of primary importance to mirror social realities to the greatest extent possible so that people can identify themselves in them. This pragmatic standpoint attempts to shorten the distance between literature and reality, so that the former functions more as an ideological weapon to enlighten the people.

Modern Chinese intellectuals interpret the concept of tragedy from two main perspectives: one is in the theatrical domain, where tragedy functions as a dramatic form closely related to the emergence of a new genre in Chinese literature, namely, the spoken drama (huaju). The other is in the aesthetic domain, where tragedy (or more specifically, the tragic) operates as a literary or philosophical idea and offers possibilities for a cross-genre development of this notion in non-dramatic literature. This dual-focus approach is paralleled by the intertwining relationship between literature and politics, which was a complicated, yet lingering problem besetting scholarly debates on tragedy in republican China. Modern intellectuals distinguished themselves by their different understandings of the inextricable link between these two; "the function of literature in the social process, and the way in which it best fulfils this function" (Eberstein, 1989: 7), thus became common questions for those attempting to either assess or reinterpret a given literary phenomenon at a certain period of time.

This study focuses on the interplay between different critical trends during the formation of modern Chinese literary discourse on tragedy between 1928 and 1937, which is usually known and referred to as "literature of the thirties" (sanshi niandai wenxue) (see for example Lee, 1986: 421; Zhu, 2007: 
120). The political concern over tragedy's role in social progress at the time makes it impossible to totally strip the Chinese perception of tragedy from the obvious pragmatic implications. Therefore, by examining theories, writings and critical views produced during this period, this study explores possible factors that have either promoted or prevented the application of theory to practice, as well as whether, and how, the long-standing problem produced by the intrinsic connection between literature and politics has left a noticeable influence on the Chinese understanding of the tragic.

\section{Theoretical Discussion: The Function of Tragedy}

The Chinese conceptualisation of tragedy in the 1930s was marked by the substantial and clear references to European theories and works. Scholars devoted themselves to translation and interpretation, particularly concerning the Aristotelian concepts of tragedy, such as mofang (imitation), lianmin he kongbu (pity and fear), yanzhong (seriousness), dongzuo (action), guoshi (tragic flaw), and xuanxie (purgation). Their discussions highlighted the artistic nature of tragedy, concern with tragedy's means of expression (through "imitation"), emotional effects (as "pity and fear"), and theme (of something serious and profound in man's spiritual world). Based on the primary understanding of Aristotle's definition of tragedy, scholars went further to debate the function of tragedy, from the perspective of both the aesthetic approach and the pragmatic approach, each with their own distinctive and different interpretations.

\section{The Aesthetic Perspective}

Discussions of the function of tragedy initially went hand-in-hand with the interpretation of the Aristotelian term "purgation" (xuanxie), which was at first perceived as an emotional effect of tragedy. Liang Shiqiu referred to xuanxie as 
the essence of an artistic task, ${ }^{1}$ and therefore explained Aristotle's definition as "containing both ethical and artistic elements" (Liang, 1928: 101) in terms of its emphasis upon tragedy's capability to "amuse the audience with a necessary cause of moral judgement" (lunli de caipan) (Liang, 1928: 102). In other words, Liang held that the usefulness of tragedy lay not merely in the emotions it aroused among the audience, but more importantly, in the process of cleansing when those emotions were stimulated, released, and finally healed through watching tragedies: "tragedy [...] extricates people from heavy emotional burdens, making them more conscious and strong-minded" (Liang, 1927: 103).

Xiong Foxi provided three different meanings for xuanxie: ${ }^{2}$ medically, it was a psychological or physical treatment; religiously, it was an emotional relief; and morally, it was a cultivated sense of justice. He suggested understanding this word as the "purgation of passions" (Xiong, 1933: 58), ${ }^{3}$ which was based on his observation of the emotional experience of watching tragedies: "there are times when we shed tears upon seeing tragedies with extremely miserable plots; however, our hearts are filled not with pain but instead with a sense of unspeakable joy-why is that?" (Xiong, 1933: 57). This question pointed to the core matter of tragedy's emotional function from the reader-response perspective, and received different answers from contemporary scholars.

Zong Baihua referred to the emotional release offered by tragedy as its "beauty" (mei), ${ }^{4}$ because people could "feel a sense of comfort and relief

${ }^{1}$ Liang Shiqiu (1903-1987): essayist, literary theorist, translator; known for his advocacy of New Humanism under the influence of Irving Babbitt, as well as his contribution to the development of theories of literary criticism with regard to the May Fourth and New Culture literary tendencies.

2 Xiong Foxi (1900-1965): playwright, educator, and practitioner of modern Chinese drama; well-acknowledged for his fundamental contribution to the development of spoken drama (huaju) in modern Chinese literature through rural drama experiments and volumes of theoretical discussions.

${ }^{3}$ He used these English words.

${ }^{4}$ Zong Baihua (1897-1986): philosopher, aesthetician; active participant in New Culture Movement. Received systematic training in philosophy in Germany; expert in Chinese aesthetics of experience (tiyan meixue). 
besides the miserable experience" (Zong, 1926-28: 531-532). He further explained how the miserable and joyful experience worked on the audience: the former related to the sympathy people showed towards the tragic hero who was suffering from a setback - "the more frustration he is confronted with, the more grief it will stimulate among the audience due to the greatness they find in him"; the latter was aroused by witnessing the tragic hero's choice of death to free himself from spiritual or physical tortures. As Zong explained, "tragedy of this kind is capable of presenting life's complexity and hardships; it easily attracts people, with its focus upon the internal facets of human existence" (Zong, 1926-28: 533-534). Therefore, to Zong, the function of tragedy lay mostly in its offering of the "opportunity to rediscover life's in-depth conflicts in ordinary daily experience", because "the true essence of human existence is the everlasting struggle for the realisation of a value beyond life; it may bring destruction to life during this process, but at the same time, an emotional release as delight and nirvana" (Zong, 1934: 67).

Li Anzhai gave an unusual explanation of why tragedy seemed appealing to people. ${ }^{5}$ He explained this appeal as a "sadistic" mentality (upon seeing others' misfortunes), or a "masochistic" mentality (the empathy and co-experiences of the painful sufferings of others), or the "distance of safety" (from real mental or physical suffering). He also explained the "unusual beauty" in certain fine tragedies: "[it is] a mentality of perfection [yuanman xinli] to harmonise all those emotional conflicts that are not easy to reconcile-a process through which a new 'unity' [zheng] and 'wholeness' [quan] is created" (Li, 1934: 87-88). To Li, the function of tragedy was the cultivation of an ideal life style which was neither self-indulgent (fangren) nor self-oppressive (yizhi):

The benefit of watching tragedies is that one can share with the tragic heroes the same experience without the need to have actually undergone those tragic events; [by doing this people can] build up an attitude of following the categorical

${ }^{5}$ Li Anzhai (1900-1985): sociologist, anthropologist, ethnologist; specialised in the study of Tibetan tribe culture. 
imperative $^{6}$ of one's conscience that is motivated by one's own inner desires, rather than being subjected to the external constraints (Li, 1934: 94).

Zhu Guangqian regarded this emotional experience as a "tragic pleasure":7 "The pain in Tragedy is felt and expressed, and as it is felt and expressed, its pent-up energy is discharged and relieved. The relief of this pent-up energy means not only the removal of high tension, but also the awakening of a feeling of vitality. So it gives rise to pleasure" (Zhu, 1987: 163-164). Zhu examined tragedy's function from the perspective of the spiritual uplift of mankind, which was "denied to him in the actual world of compromise and mediocrity" (Zhu, 1987: 88): "Tragedy, in a word, transports us from the actual world of ordinary experiences to an ideal world of great actions and strong passions, and thus cures us of the nausea of sordidness and mediocrity which our daily routine constantly produces in us" (Zhu, 1987: 188).

Qian Zhongshu based his elaboration of tragedy's emotional effects upon the critique of traditional Chinese dramas. ${ }^{8}$ He compared "Shakespeare's Antony and Cleopatra and Dryden's All for Love" with "Pei Jen-fu's Rain in the Oil Trees [Wutong yu] and Hung Shen's The Palace of Everlasting Life [Changsheng dian]" (Qian, 1935: 38) (yet without explaining why he chose them). ${ }^{9}$ To him, these two Chinese dramas were not tragedies, because they were unable to uplift the audience to any higher level of emotional experience beyond sympathy - "the tragic characters [...] are not great enough to keep us

${ }^{6}$ He used the English words here.

7 Zhu Guangqian (1897-1986): aesthetician, literary theorist and critic, translator; one of the pioneering forerunners for the foundation of aesthetic studies in 20th-century China. Most celebrated for his series of aesthetic monographs as well as his translated works of Plato, Goethe, Hegel and Croce.

8 Qian Zhongshu (1910-1998): writer, literary scholar, famous for his broad knowledge of both Chinese and Western literary traditions; well-established in the field of cross-cultural literary creativity and studies.

${ }^{9}$ Rain in the Oil Trees (Wutong yu) is a four-act play written by Bai Pu (1226-1306) in the Yuan dynasty; The Palace of Everlasting Life (Changsheng dian) is a 50-scene play written by Hong Sheng (1645-1704) in the early Qing dynasty. Both of these plays tell the tragic love story of Princess Yang Yuhuan and the Emperor Xuanzong of the Tang Dynasty. 
at a sufficient psychical distance from them" (Qian, 1935: 38-39). Here, Qian shared the same opinion with Zhu Guangqian in suggesting that tragedy be "distanced' and 'filtered' through the medium of art" (Zhu, 1987: 39), as "[m]oral sympathy often destroys distance and so spoils the effect of tragedy" (Zhu, 1987: 58). In this regard, Qian referred to the two well-celebrated Chinese tragedies-Zhaoshi guer (The Orphan of Zhao) and Dou E yuan (The Injustice to Dou E) - as examples. According to Qian, the emotional effects of these two plays were largely weakened by either the "characteristic poetic justice in the last act [of Dou E yuan]", or the unequal strength between the "competing forces" that led to the self-division of the protagonist Cheng Ying in Zhaoshi guer (Qian, 1935: 41-43). Consequently, Chinese dramas of this kind, as Qian claimed, needed to be separated from "real tragedies", because they failed to provide the audience "with the calm born of spent passions, or what Spinoza calls acquiescentia, with the workings of an immanent destiny" (Qian, 1935: 38).

\section{The Pragmatic Perspective}

The above discussions concentrated on the emotional function of tragedy; they explored the role certain sentiments played in helping the audience with either the transformation of daily ordinariness through artistic activities, or the cultivation of a positive attitude to life. In the meantime, another perspective prevailing during this time highlighted tragedy's function for the enlightenment of society. Ouyang Yuqian promoted a dramatic art presenting faithfully daily life and social reality: "theatre mirrors and is determined by society" (Ouyang, 1929: 2). ${ }^{10}$ According to Ouyang, theatre reflected society in a way that helped to reconstruct and reradiate the true image of the world during the process of representation, and thus enabled people to know life and themselves better by providing new driving forces for their development- "this is the true mission for theatre" (Ouyang, 1929: 4). Therefore, he advocated "a new kind of drama

10 Ouyang Yuqian (1889-1962): playwright, Peking opera actor and film director. He devoted much of his career to the discussion and practice of theatrical creativity, and was considered one of the founders of modern Chinese spoken drama (huaju). 
[tragedy] that did not satisfy itself solely with recreation" (Ouyang, 1929: 5), since "the old dramatic form is no longer capable of conveying the feelings and thoughts of modern people" (Ouyang, 1929: 32-33).

Xiong Foxi directed his interpretation of tragedy's function to the Chinese literary and social realities in the 1930s. Tragedy, he claimed, was the most solemn artistic form of poetry, because it could stimulate people's consciousness of respect and sympathy: "We cannot help feeling empathetic towards those tragic heroes when watching Shakespeare's Hamlet and Ibsen's Ghosts; we are more likely to experience a sense of awe out of pity when seeing Yue Fei being stabbed in the back in return for his loyalty to the country" (Xiong, 1933: 70-71). ${ }^{11}$ However, emotions of this kind were lacking in China, which was at that time "a country where a pestilential atmosphere of coldness and gloominess prevails": "Look at the present China! Where exactly are sympathy and respect?" (Xiong, 1933: 71). Consequently, Xiong regarded tragedy as primarily a wake-up call for the nation: "We should brook no delay in raising and promoting the art of tragedy, if we want a silver lining and the drop of a sympathetic tear to be found in China" (Xiong, 1933: 71).

Zhang Min also saw tragedy as the reflection of social reality; he elaborated this point by discussing the relationship between the writer and his works. ${ }^{12}$ In his opinion, the origin of tragedy lay in various kinds of "tragic realities" (beiju de xianshi), from the very beginning of primitive society to the civilised societies of today (Zhang, 1936: 2); hence, "tragedy was not a mere creation of the playwright's subjective will, but a reflection of the emotions and lives of those living in the actual scenes of tragic realties" (Zhang, 1936: 3). To Zhang, drama needed to interact with the audience and to stimulate certain emotions among them in order to achieve its dramatic effects: "The solemnity

\footnotetext{
${ }^{11}$ Yue Fei (1103-1142): a Chinese military general and national folk hero in Southern Song dynasty. Famous for his bravery in the war between the Southern Song and Jin tribes. Despite great contributions to the defence of his country, Yue Fei was framed and put to death by the Southern Song government.

12 Zhang Min (1906-1975): theorist and educator of dramaturgy, director; one of the founders of the Left League campaign.
} 
[yansu xing] in tragedy's theme produces a serious attitude, which is one of the most important features distinguishing tragedy from other dramatic forms. Sympathy [tongqing $x i n g$ ] is also one of the emotions stimulated by tragedy; in fact, it can be found in tragedies of all ages, with its contents varying according to the changing times" (Zhang, 1936: 11-12). Based on this point of view, Zhang emphasised the playwrights' responsibility to ensure that the emotions and thoughts they were trying to convey had certain universal meanings, because "the more profound sympathy a tragedy is able to stimulate, the higher its value and the better its effects" (Zhang, 1936: 17).

\section{The Shared Focus}

As stated above, two different perspectives remained visible in the Chinese interpretation of the function of tragedy in the 1930s, as there existed both an aesthetic interest in tragedy's sublimation or idealisation of daily experience through artistic expressions (promoted by Zhu Guangqian, Zong Baihua, and Li Anzhai), and a pragmatic concern over tragedy's faithful presentation of social reality (advocated by Ouyang Yuqian, Xiong Foxi, and Zhang Min). However, these two perspectives were not exclusively confined to any particular groups of scholars; to be exact, it was not unusual for some "social realists" to also recognise certain aesthetic or philosophical features in the art of tragedy.

For example, Ouyang Yuqian, although not directly quoting Aristotle, acknowledged that "[t]he emotional experience of watching a tragedy involved both pity [lianmin] and fear [kongju]": "the former is the sympathy for the miserable circumstances the protagonist encounters, the latter is the empathy for the same situation falling upon the audience themselves. These emotions are extremely noble as it produces all the peace and comfort in the world" (Ouyang, 1929: 35). Apart from insisting on the faithful presentation of social reality, Ouyang also considered the capability to "purify the spirit" (shi jingshen jinghua) as one aspect of tragedy's function, hence the writer's role in artistic creativity: "The rich compassion provides an artist with both his title and the value of his works, which lies in the profound emotions he is able to evoke" 
(Ouyang, 1929: 35).

Xiong Foxi shared a similar perspective. He held that "[w]e would easily sympathise with the characters in past great Western tragedies, whose good intentions were repaid by evil results; we would also easily be afraid of encountering the same miseries, especially when this empathy extends to the entire human race" (Xiong, 1933: 60). But Xiong tried to associate this emotional effect with some traditional Chinese ideas of morality: he perceived tragedy "from a moral perspective" (daode de yanguang), considering it to be functioning in a way which could cultivate a sense of justice (zhengyi) and conscience (liangxin) in the audience through a method called "like cures like" (yi du gong du): "the more the conscience is being cultivated, the stronger and healthier these emotions could be; the sense of justice would also be reinforced during this process" (Xiong, 1933: 60-61).

This may suggest a different view to that found in some existing Chinese scholarship, which divides intellectuals who discussed the concept of tragedy in the 1930s according to their membership in literary (but in fact largely political) groups or societies - the left-wing camp and the liberal camp ${ }^{13}$-and thus based these two camps' interpretations of the concept of tragedy on an anticipated bifurcation between literary utilitarianism and literary aestheticism (see for example Xie, 2014: 204-218; Zhu, 2007: 120-141; Qian, Wen \& Wu, 1998: 191-214; Fan \& Zhu, 1993: 561-620). According to this classification, scholars such as Ouyang Yuqian, Hong Shen, Ma Yanxiang, Xiong Foxi, and Zhang Min were the leftists and ought to possess a clear political intention in their literary propositions, while Liang Shiqiu, Zong Baihua, and Li Anzhai were the liberalists and should therefore keep a relatively neutral standpoint regarding the politicisation of literature. However, the above examination shows that the viewpoints between these two camps, at least in the reading of

\footnotetext{
13 An organisation of leftist writers founded in Shanghai on March 1930; also known as the Left League (Zuolian). The major purpose was to promote proletarian art and socialist literature to support the ideological rivalry of the Communists against the Nationalist government. Used to be the largest literary group in the 1930s, with its active engagement in a series of running debates; it was disbanded in 1936.
} 
the tragic, were not so sharply contrasted: the shared focus on the aesthetic features of tragedy, between the so-called "leftist school" and "liberal school", stands as an example. In this respect, certain "shared literary values cut across the membership lines of literary groups" (Denton \& Hockx, 2008: 8) in the theoretical construction of the concept of tragedy at this time.

To sum up, modern Chinese scholars in the 1930s understood the function of tragedy mainly from two angles: the aesthetic perspective, concerned with the relationship between tragedy and emotional release, and the pragmatic perspective, concentrated on the relationship between tragedy and social reality. These two perspectives overlapped when acknowledging the emotional effects of tragedy and its spiritual benefit to the audience. This situation offered more space for the growth of a non-utilitarian perspective, either exploring the aesthetic attributes of tragedy or investigating the typical Chinese cultural mentality. However, taking into consideration the rising political concern over the role literature played in social transformation at this time, the question of whether and how these theoretical discussions actually influenced contemporary indigenous literary creativity awaits further examination.

\section{Literary Practice: The Debate Between Aesthetics and Literary Realism}

Modern Chinese theatre reached maturity (Nobel, 2003: 446) in the 1930s with the publication of Cao Yu's tragedies, which, inspired by Euro-American tragic traditions, were a "popular success" (Goldman \& Lee, 2002: 239) both at this time and in the following decades. Cao $\mathrm{Yu}$ is generally regarded as one of the most successful modern Chinese playwrights. ${ }^{14}$ Interpretations of his tragedies vary across time and literary trends; aesthetic and political perspectives alternate and compete with each other. This section examines the

${ }^{14}$ Cao Yu (1910-1996): penname of Wan Jiabao. One of the most important playwrights in modern Chinese literature; the forerunner of Chinese spoken drama (huaju). Major plays include Leiyu (Thunderstorm, 1934), Richu (Sunrise, 1936), Yuanye (The Wilderness, 1937), and Beijing ren (Peking Man, 1940). 
critical debates over Cao Yu's most famous tragedy, Leiyu (Thunderstorm, 1934), for a concrete demonstration of how the playwright's efforts to "transplant the European stage" (McDougall \& Louie, 1997: 28) of the tragic to China were interpreted and accepted by his audience in the 1930s. The contention between aesthetic purposes and political concerns in assessing the play signified, to a large extent, a contemporary critical trend which saw the conflation of debates on aestheticism and realism, and thus served as an example of the actual impact of this conflation on the interpretation of the tragic in the 1930s Chinese literary field.

\section{Leiyu and its Foreign Inspiration}

Having a high status in modern Chinese literature, Leiyu is referred to as "the most famous dramatic work of the pre-war period and possibly the most performed play in the modern Chinese theatre" (McDougall \& Louie, 1997: 177). ${ }^{15}$ It was finished in 1933 and first published in 1934, and was followed shortly thereafter by several stage performances in both China and Japan, eliciting positive responses (for details, see Zhang, 2003: 42-57; McDougall \& Louie, 1997: 177). The dramatic structure develops around a series of chaotic events, presenting the disintegration of a patriarchal family triggered by incestuous passion, moral degradation, ferocious revenge, and predestined retribution. The capitalist and coalmine owner, Zhou Puyuan, drove away the servant maid, Shiping, whom he formerly seduced, so that he could marry a young girl from another wealthy family. Some thirty years later, the eldest son of the Zhou family, Zhou Ping, had secret sexual relationships with both his stepmother, Fanyi, and the servant girl, Sifeng, not knowing that the latter, who was pregnant with his child, was, in fact, his half-sister. On the other hand, Zhou Puyuan was in fierce confrontation with a group of workers from his coalmine, and his unrevealed second son with Shiping, Lu Dahai, was the

15 A four-act play depicting the sudden exposure of the unrevealed secrets and sins in a big feudal family, and the destruction of the family members, who were victims of uncontrolled passion, oppression, revenge, and incestuous love. First published in Wenxue jikan (Literary quarterly) 1, no.3 (1934): 161-244. 
leader of the strike action. In order to dissuade the youngest son, Zhou Chong, from having affection for Sifeng, Fanyi called the girl's mother, Shiping, to the Zhou house to take her daughter away; subsequently, the complex relationships among these characters were gradually revealed, leading them to their respective tragic ends.

Cao Yu's critics associated Leiyu with various foreign models. Li Jianwu pointed out two implicit European inspirations-Euripides's Hippolytus (428 BC) and Racine's Phèdre (1667)-as borrowings for the incestuous story between stepmother and stepson, together with the psychological description of the female character, Fanyi, as a woman driven by a strong desire for revenge (Li, 1936: 120-122). ${ }^{16}$ Tian Han referred to Leiyu as "a mixture of several famous dramas", 17 such as "Sophocles's Oedipus the King [429 BC], Ibsen's Ghosts [1881], and Galsworthy's Strife [1909]" (Tian, 2000: 287). ${ }^{18}$ Other critics like Ouyang Yuqian, Guo Moruo, ${ }^{19}$ and Zhou Yang, ${ }^{20}$ all regarded Leiyu as a tragedy of fate (mingyun beiju), which bore great similarity to the ancient Greek tragedies (see Tian \& Hu, 1991: 706, 760, 828).

16 Li Jianwu (1906-1982): writer, dramatist, and literary critic; member of The Literary Association (Wenxue yanjiu hui), leader of the drama movement in Shanghai during the Anti-Japanese War; known for his distinctive use of romanticism in the expression of the characters' inner activities.

17 Tian Han (1898-1968): playwright, poet, literary critic and activist, pioneering figure in modern Chinese theatre, one of the founders of The Creation Society (Chuangzao she) and League of Left-Wing Writers (Zuoyi zuojia lianmeng); major works include Kafei dian zhi yiye (A Night in a Café, 1922), Huohu zhiye (The Night the Tiger was Caught, 1924), and Nangui (Return to the South, 1929).

18 Tian Han, "Baofengyu zhong de Nanjing yitan yipie" ("A Glance at the Art Circle of Nanjing in the Storm"), first published in Xinmin bao rikan (Journal of Xinmin Newspaper), June 9, 10, 12, 14, 29 (1936), reprinted in Tian Han quanji, di shiwu juan, wenlun (Complete works of Tian Han, vol. 15, Literary Criticism) (Shijiazhuang: Huashan wenyi chubanshe, 2000), 282-96.

19 Guo Moruo (1892-1978): poet, historian, archaeologist, one of the leading writers in 20th Chinese literature; especially well-known for his contribution to modern and contemporary Chinese academic traditions. His well-established works were collections of poems such as Nüshen (Goddess, 1921), Xingkong (Star Skies, 1923), and historical plays such as Quyuan (1942), and Hufu (The Tiger Tally, 1942).

${ }^{20}$ Zhou Yang (1908-1989): literary theorist and activist, translator; one of the leaders of the League of Left-Wing Writers (Zuoyi zuojia lianmeng); advocate of Marxist theories and the Soviet literary realist approach. 
However, the playwright himself hesitated to acknowledge this connection. Shortly after the publication of Leiyu, Cao Yu clearly rejected the idea of relating this play to any particular foreign work or author: "To be honest, this [the idea that I am a follower of Ibsen and that certain parts of the play are inspired by Euripides's Hippolytus or Racine's Phèdre] has more or less surprised me. [...] I have tried my best but still do not reckon there is any intentional imitation of any author in this play" (Cao, 1996b: 5). ${ }^{21}$ On the other hand, Cao had admitted his indebtedness to ancient Greek plays before this declaration: "Someone claims that there is an influence from Ibsen in this play [Leiyu], but I would rather say there is an influence from ancient Greek plays" (Cao, 1935: 35). He further explained this influence in a later article by referring to the use of the Prologue and Epilogue to "function more or less as a Greek chorus in leading the audience into a wider sea of emotions and thoughts" (Cao, 1996b: 14). These somewhat self-contradictory statements showed Cao's ambiguous attitude toward the foreign influences he received, the motivation of which gave room to some speculation.

\section{A Tragedy of Fate, a Social Tragedy, or Something Else?}

Regarding Cao Yu's reluctance to acknowledge his foreign inspiration, Joseph Lau suggests that it may be because he mistakenly confused "the question of influence with imitation" - the latter of which "he was ashamed [of]" (Lau, 1970: 8). According to Wang Lieyao, the well-internalised incorporation of foreign influences in Cao's literary practices makes it "relatively hard to trace and orient any single foreign writer in his artistry" (Wang, 2002: 361); hence to simply associate him with any individual writer is largely one-sided. Another option this study would like to suggest is that Cao $\mathrm{Yu}$ wanted to stress his disagreement with certain contemporary interpretations in the reading of his play, as a further look at those comments Leiyu received in the 1930 s shows that there were significant differences between the critics' reviews and the playwright's own intentions.

21 Cao Yu, "Leiyu xu" (The preface to Thunderstorm), first published in 1936. It was reprinted in Tian and Liu (1996: 5-15). 
One of the prevailing opinions in the 1930s was that Leiyu was a tragedy of fate, which resulted in a mixed reception from critics. Li Jianwu considered the concept of fate (mingyun guannian) "the most powerful, invisible yet penetrating force" (Liu, 1936: 116-17) in Leiyu. He differentiated it from that of the ancient Greek tragedies, in that the concept of fate in this play was presented not as retribution from the heavens but as an impulse for revenge-first in Zhou Fanyi and then in Lu Dahai-which served as "the hidden impetus to the plot development" (Liu, 1936: 118). In view of this difference, Li held that the mainspring of Leiyu was not certain mysterious, unpredictable forces which operated outside human society, but "a complexity of personal relations and psychologies" that led the characters to their mental and physical destruction. Li thought this was a successful achievement for the playwright (Liu, 1936: 118).

In contrast, other scholars criticised this expression of the concept of fate and therefore questioned Leiyu's value. According to Guo Moruo, what Cao attempted to write was "a Greek-style tragedy of fate"; this "old-fashioned perception of the tragic" no longer fitted into modern times when "people have already become masters of their own fortunes" (Guo, 1936: 45). As a result, Guo found the entire play to be "shrouded by a dense atmosphere of old moral values and hence lacking in initiative", and attributed this weakness to "the playwright's lack of awareness" of the present situation (Guo, 1936: 45). Tian Han also criticised the play for simply basing the series of tragic events on "irresistible fate" (bu kekang de mingyun). He proposed lending the play a more "critical" perspective-to "revise this anachronistic tragedy of fate [yunming beiju] into a social tragedy [shehui beiju]" in order to "be responsible towards the audience" (Tian, 2000: 288), because "the young generation which has been toughened by the May Fourth Movement" would rather "fight bravely against those evil makers" than "submit to the cruelty of 'fate'" (Tian, 2000: 287).

Such criticism became even stronger when Richu (Sunrise, 1936) appeared with its relatively more explicit thematic concern with the darkness 
of society. ${ }^{22}$ It was thus placed, by critics, in sharp contrast with Leiyu: Ouyang Yuqian regarded Richu as one step forward from Leiyu, because the latter "is embedded too much with a tragic sense of fate" (Ouyang, 1991: 706); ${ }^{23}$ Zhou Yang termed the concept of fate in Leiyu as "fatalism" (suming lun), which "greatly reduce[d] the ideological significance of this play" and therefore was "extremely harmful to the general audience, whose simple minds would easily be affected by a notion of predestination and kinship enmity" (Zhou, 1937: 1316). It is noticeable that the above criticism more or less labelled the concept of fate in Leiyu as a spiritual heir to the ancient Greek tragedies, which they regarded as outdated and inappropriate for the social circumstances at the time. (Even Li Jianwu, who thought highly of this play, rejected the idea of providence or heavenly punishment.) This may, to some extent, explain the playwright's reluctance to admit his foreign influences, as Cao Yu used to be "frightened" by those criticisms which brought him feelings of "inferiority" and "incompetence" (Cao, 1996b: 6).

As a matter of fact, Cao Yu's own understanding of Leiyu's theme and philosophical implications was totally different. In his view, what Leiyu conveyed was neither "an idea of karma" (yinguo) nor "heavenly retribution" (baoying), but a sense of "cosmic cruelty" (tiandi jian de canren) that was best represented by the sudden deaths of Sifeng and Zhou Chong, who did nothing to deserve such treatment (Cao, 1996b: 7). Here, Cao admitted the existence of a certain force behind such "cruelty" and "cold-bloodedness", but did not equate it with the Hebrew perception of God, the Greek dramatic notion of fate, or the modern concept of the "law of nature" (ziran de faze) (Cao, 1996b: 7). Rather, he depicted this "complex and yet primitive sentiment" as, vaguely, "an inexplicable mystery" (moming qimiao de shenmi) (Cao, 1935: 35) that was "too overwhelming and complicated to be either properly named or described

\footnotetext{
22 A four-act play written by Cao Yu in 1936, presenting the extravagance and decadence of metropolitan life; first published in Wenji yuekan (Literary quarterly) 1-4 (1936).

${ }^{23}$ Ouyang Yuqian, "Richu de yanchu" (The staging of Sunrise), first published in Richu shouci yanchu tekan (Special issue for the debut of Sunrise), 1937, reprinted in Tian and Hu (1991: 705-706).
} 
of its true features" (Cao, 1996b: 7); ${ }^{24}$ "this inexplicable mystery finally cost an innocent girl [Sifeng] her life. Couldn't this primitive psychology sometimes excite the heart and soul of civilised mankind and lead him towards an awareness of the deeper and more fathomless mystery in nature?" (Cao, 1935: 35). In this respect, Zhu Guangqian's comments provided another explanation of this thematic concern, that it "generally gives us the impression that there is in the universe a power which is neither controllable by human will, nor intelligible to human understanding, and that this power is blind to the distinction of right and wrong and it crushes the virtuous as well as the wicked" (Zhu, 1987: 245).

However, Cao Yu's contemporary critics did not accept this viewpoint. Rather than examine its largely abstract philosophical ideas, ${ }^{25}$ scholars in the 1930s were more interested in exploring the realist elements in Leiyu that related to heated social issues such as personal freedom, class struggle, and social transformation. Shortly after Leiyu's publication, comments were made on the pragmatic aspect of the play, considering it a condemnation of the capitalist social system: "it is an exposure of a Chinese capitalist family with a penetrating analysis that goes deep into their sins, covered by wealth" (Bai, 1935a); "the obscene and evil ugliness of the capitalist family is ruthlessly revealed through the presentation of their complicated love affairs; the fierce thunderstorm in the summer's night is indicative of the crumbling of this class" (Bai, 1935b: 39). Other reviews added an anti-feudal significance to the play's characters: first, Fanyi, who as a female victim of feudalist morality (Zhang, 1939), revealed with her death the cold-bloodness and the crisis of the feudalist system (Zhou, 1937); then, Lu Dahai, who, by confronting Zhou Puyuan, signified the rise of the much oppressed working-class (Liu, 1936) in contrast to the decay of the feudalist forces. ${ }^{26}$ According to these criticisms,

24 English translation taken from Lau (1970: 13).

25 Zhang Geng once described his reading experience of Leiyu as "unempathetic" and "alienated", and that it made him unable to identify with the author's world. See Zhang (1936: 60).

26 As a matter of fact, the characterisation of Lu Dahai was more often used as a negative example to show Leiyu's weakness, because some reviews held that the portrayal of him only as a part of a complex kin relationship, rather than a representative of social conflicts, was 
Leiyu as a social tragedy needed to make the best use of its subject matter in exploring "the confrontation between two social forces" rather than "the entanglement among kinship" in order to evoke "the predestined collapse of an out-dated feudalism" (Zhou, 1937: 1317).

This perspective was in line with the pragmatic view promoted by Ouyang Yuqian, Xiong Foxi, and Zhang Min in theoretical discussions about the function of tragedy as a means of social enlightenment and critique. The impact of this viewpoint is long-term, as the historical background of the play remains one important part of the analysis in later research: scholars refer to Leiyu as "the tragedy of the old marriage system, the feudal family structure, the oppression of the lower classes, the corruption of urban capitalists, and the frustrations of young intellectuals" (Lee, 1986: 465), which were "the most sensitive issues involved in the May Fourth Movement" (Lau, 1970: 7). To them, this was one of the reasons for its popularity among the Chinese in the 1930s, when the audiences "[were] themselves trapped in an ongoing historical thunderstorm" (Wang, 2010: 507; see also Lau, 1970: 6; Nobel, 2003: 447).

This interpretation was, again, in sharp contrast to Cao Yu's purpose of writing. Two years after the publication of Leiyu, Cao referred to those literary realist readings and criticisms as being "far beyond my own understanding of this play" (Cao, 1996a: 23), ${ }^{27}$ because it was not his intention "to correct, criticize, or satirize anything" (Cao, 1996b: 7): ${ }^{28}$ "What I wrote was a poem-a narrative poem that, [...] in spite of its involvement with something real and practical (such as the strike), was by no means a social problem play" (Cao, 1935: 34). On the contrary, he insisted on the thematic concern over human beings' vain struggle under the dominance of a mysterious external force: "I portrayed the universe [yuzhou] in Leiyu as a cruel well [canku de jing] in which

\footnotetext{
"gloomy" and thus "a complete failure". See the comments in Tian (2000: 287-288) and Zhou (1937: 1317).

${ }^{27}$ Cao Yu, "Leiyu ri yiben xu" (Preface to the Japanese translation of Thunderstorm), first published in the Japanese version of Leiyu by Sairen Press in 1936, translated and reprinted in Tian and Liu (1996: 22-24).

${ }^{28}$ English translation taken from Lau (1970: 6).
} 
a person-no matter how hard he cried out in pain-could simply find no way to escape once falling into this dark hole" (Cao, 1996b: 8). Here, Cao valued the aesthetic distance between the audience and his play; he suggested taking Leiyu as "a myth" or "a story" (Cao, 1935: 34) in order to better appreciate the "poetic sentiment" (shiyang de qinghuai) (Cao, 1996b: 14). To him, "the plot develops in a way too horrible to be emotionally accepted in its secret, unknowable implications" (Cao, 1996b: 14); therefore, the Prologue and Epilogue served as a "veil of emotional distance so as to mitigate the intensity of the emotional and rational shock" (Cao, 1996b: 14). ${ }^{29}$ Yet this proposal was nevertheless ignored: both the Prologue and Epilogue were deleted from the script after the first few stage performances both out of consideration of the play's length, and their "irrelevance" to the theme (See Cao, 2000: 384; Wang, 1994: 244-245). Zhou Yang also suggested not deliberately creating a so-called "emotional distance" between the audience and the play, because it would be better to "just let the audience be frightened and shocked by the sinfulness revealed before them, and cry out without control for the coming of a thunderstorm that shakes everything!" (Zhou, 1937: 1317).

\section{Behind the Disputes}

According to later scholars, the controversy over Leiyu's theme revealed a paradox regarding the acceptance of this play in the 1930s Chinese literary field, as audiences were engaged in reading and appreciating Leiyu with both "an unprecedented enthusiasm" and "an overwhelming tendency of misinterpretation" (Qian, Wen \& Wu, 1998: 421). In fact, this problem emerged almost immediately after Leiyu was put on stage in 1935. The comments of the editors of Zawen (Essay) provided an example, as they noticed a big gap between the audience's reaction and the playwright's intention when the play was performed in Tokyo: "According to the actual effect of the performance, what the audience have sensed from the play is a good exposure of the reality and sarcasm of the declining class-this is far

29 Ibid. 
from the author's motive as stated below" (The Editors, 1935: 34). Some scholars consider this difference in interpretation as a "discrepancy between the author's subjective intention and his works' objective effect", and see it as rather "common" (Yue, 2015: 215) because "the separation between the author's spiritual world and the audience's horizon of expectation" leads to a divergence in the focus of literary interpretation (Wang, 1994: 244).

Yet, this study would like to suggest that this "paradox" revealed the opposition between the aesthetic and realist discourses in the reading of the tragic in the 1930s. As can be seen from the above analysis, it is clear that Cao Yu's original concern was more with the aesthetic features of the play; but a literary realist viewpoint concentrating on Leiyu's intimate relationship with prevailing social issues was remarkably influential and somewhat triumphed in the field of literary criticism. It not only determined to a great extent the play's popularity, but also, in return, changed Cao's attitude. To Cao, the criticism of the "self-contradiction between his worldview and his artistic approach" (Zhang, 1936: 65) was so pervasive that it made him gradually become less resolute in negating the implication of social criticism in Leiyu: "Quite possibly, when I came close to finishing the play, it might be that I was seized by a sudden passion so overwhelming that I could not but seek to release it in vilifying the Chinese family system and society" (Cao, 1996b: 7). ${ }^{30}$ This was perhaps in order to not be side-lined in literary circles. ${ }^{31}$

In summary, the literary realist viewpoint prevailed in the evaluation and acceptance of Leiyu in the 1930s. It obviously differed from the situation in contemporary theoretical discussions, where the pragmatic concern with

${ }^{30}$ English translation taken from Lau (1970: 6).

${ }^{31}$ Cao Yu completely converted to a standpoint of social criticism in the 1950s, and confessed his "backwardness" in Leiyu regarding the concept of fatalism. He revised the play, deleted the Prologue and Epilogue, and made Lu Dahai more distinctly a representative of the working class with strong political awareness. See the detailed discussion in Liao (1963: 81-99), and and Cao Yu's own accounts of his changing standpoint in Cao Yu, "Wo dui jinhou chuangzuo de chubu renshi" (Preliminary thoughts on how to proceed with my writing in the future), first published in Wenyi bao (Newspaper on literature and art) 3(1) (1950) and reprinted in Tian and Liu (1996: 44-48). 
tragedy's socio-political function was less dominant in its relation to the aesthetic interpretation of the concept of tragedy. This has to be understood in the context of the reception of the tragic, and the Chinese literary and social circumstances of the 1930s, when, as summarised by later scholars, the emphasis on "the social function of literature and arts" (Tong, 1997: 2) required "a criticism and exposure" of social problems in literary creativity (Ge, 2014: 283). The literariness and artistry of Leiyu was easily ignored, and gave way to a rather secular and pragmatic interpretation.

\section{Conclusion}

This study has examined the construction of the Chinese literary discourse on tragedy in the 1930s, the characteristics of which can be summarised as follows.

First, the aesthetic and pragmatic readings of the tragic remained visible in both theory and practice. In theoretical discussions, the two perspectives focused on either the emotional or societal function of tragedy, and shared the same attitude to acknowledging certain aesthetic features of it. In literary practice, these two perspectives competed with each other for an authoritative interpretation of Cao Yu's tragic idea. The latter prevailed in literary criticism, and thus largely determined the reception of Leiyu among its contemporary audiences.

Second, regarding the formation of a modern Chinese tragic tradition in the 1930s, theory was not totally applied to practice, as the pragmatic perspective did not seem to offer any space for the aesthetic perspective in the contemporary reading of Leiyu. In other words, despite the coexistence of literary utilitarianism and literary aestheticism in theoretical discussions, the majority of critical reviews were concerned with the literary realist aspects of works written during this period, and therefore read them with regard to their social implications and significance regardless of the writers' political inclinations. The reception of Leiyu was indicative of this trend, where the 
pursuit of aestheticism had eventually been interpreted from, and included in, the political realist concern.

Third, the Chinese reception of the tragic in the 1930s was not a simple issue of literary appropriation, but was largely determined by the interplay between several cultural, social and political elements which served as a direct response to socio-political transformation at the time. As a result, the 1930s Chinese tragic tradition is distinctive, and has certain secular, pragmatic features: rather than emphasising the ultimate existence of an omnipotent power beyond human control, it concentrated on revealing earthly matters resulting from certain prevailing social and political problems. This literary orientation connected the tragic with reality, rather than with mysterious, unpredictable forces that distanced tragedy from the audience's daily lived experiences. In this respect, Cao Yu's Leiyu has inherited features from the Greek perception of fate, but has received sharp criticism from the contemporary intelligentsia; this case serves as an example of the rejection of this Greek perception in the 1930s Chinese literary discourse.

As stated above, the Chinese appropriation of the tragic in the 1930s was permeated by an intricate and changing relationship between aesthetics and literary realism. This set the tone for modern Chinese understandings of tragedy, making it a unique literary appropriation and reflection of the Chinese experience of social and political transformation in the modern period. Rather than formulate a definition of tragedy, scholars at this time were more interested in exploring its function; in other words, they asked what the use of tragedy was, rather than what it actually is. Therefore, the idea of the tragic in 1930s Chinese literature was in the first place not an aesthetic approach, providing the audience with pity and fear to purify their minds and souls, but a tool that transferred sympathetic feelings of grief and indignation into a practical concern with current socio-political affairs, and into a desire to make a change. The 1930s Chinese reception of the tragic, in this case, served as one telling example of the intertwining relationship between literature and politics that besieged modern Chinese literary discourse at the time. 


\section{References}

Bai, Mei (1935a), "Leiyu pipan" (Criticism of Thunderstorm), Dagong bao, August 20-23.

Bai, Ning (1935b), “Leiyu zai Dongjing gongyan" (The performance of Thunderstorm in Tokyo), Zawen 1: 39-40.

Cao, Yu (1935), "Leiyu de xiezuo" (The writing of Thunderstorm), Zawen 2: 34-36.

- - (1996a), "Leiyu ri yiben $\mathrm{xu}^{\prime}$ (Preface to the Japanese translation of Thunderstorm), 22-24, in Tian Benxiang and Liu Yijun (eds.), Cao Yu quanji, di wu juan (Complete works of Cao Yu, vol. 5), Shijiazhuang: Huashan wenyi chubanshe.

- - (1996b), "Leiyu xu" (The preface to Thunderstorm), 5-15, in Tian Benxiang and Liu Yijun (eds.), Cao Yu quanji, di yi juan (Complete works of Cao Yu, vol. 1), Shijiazhuang: Huashan wenyi chubanshe.

- - (1996c), "Wo dui jinhou chuangzuo de chubu renshi" (Preliminary thoughts on how to proceed with my writing in the future), 44-48, in Tian Benxiang and Liu Yijun (eds.), Cao Yu quanji, di wu juan (Complete works of Cao Yu, vol. 5), Shijiazhuang: Huashan wenyi chubanshe.

-- (2000), "Richu ba" (Postscript of Sunrise), 374-392, in Cao Yu wenji, shang (Collection of Cao Yu's works, Part 1), Beijing: Huaxia chubanshe.

Denton, Kirk A., and Michel Hockx (eds.) (2008), Literary Societies of Republican China, New York: Lexington Books.

Eberstein, Bernd (ed.) (1989), A Selective Guide to Chinese Literature 1900-1949, vol. 4, The Drama, Leiden: E.J. Brill.

Fan, Boqun, and Zhu Donglin (eds.) (1993), 1898-1949 Zhongwai wenxue bijiao shi (History of Chinese and foreign comparative literature, 1898-1949), Nanjing: Jiangsu jiaoyu chubanshe.

Ge, Guilu (2014), "Cao Yu Leiyu-huigui dao 'Leiyu xu' de yitu jieshi” (Cao Yu's Thunderstorm-return to the revelation of intentions in "Preface to Thunderstorm"), 281-287, in Bijiao wenxue zhilu: jiaoliu shiye yu chanshi fangfa (The road of comparative literature: communicative vision and the interpretative approach), Shanghai: Sanlian shudian.

Goldman, Merle, and Leo Ou-fan Lee (eds.) (2002), An Intellectual History of 
Modern China, Cambridge: Cambridge University Press.

Guo, Moruo (1983), "Guanyu Cao Yu de Leiyu" (On Cao Yu's Thunderstorm), 760-761, in Zhang Chenghuan, Guo Moruo lun chuangzuo (Guo Moruo on literary creation), Shanghai: Shanghai wenyi chubanshe.

$\mathrm{He}$, Ping, and Ren Changming (2013), "Qianxi gu Xila beiju dui Leiyu de yingxiang" (A brief discussion of the influence from ancient Greek tragedy on Thunderstorm), Xiju wenxue 8: 107-110.

$\mathrm{Hu}$, Shi (1922), "Wo de qilu" (My crossroad), Nuli zhoubao, June 18.

Lau, S.M. Joseph (1970), Ts'ao Yü, The Reluctant Disciple of Chekhov and O'Neill: A Study in Literary Influence, Hong Kong: Hong Kong University Press.

Lee, Leo Ou-fan (1986), "Literary Trends: the Road to Revolution 1927-1949", 421-491, in John K. Fairbank and Albert Feuerwerker (eds.), The Cambridge History of China vol. 13: Republican China, 1912-1949, Part 2, Cambridge: Cambridge University Press.

Li, Anzhai (1934), "Mei de fanchou yu beiju" (The domain of beauty and the tragedy), 86-94, in Meixue (The aesthetics), Shanghai: Shijie shuju.

Liao, Li (1963), "Tan Cao Yu dui Leiyu de xiugai" (On Cao Yu's revision of Thunderstorm), Zhengzhou daxue xuebao, zhexue shehui kexue ban 1: 81-99.

Liang, Shiqiu (1928), "Yalishiduode de Shixue" (On Aristotle's Poetics), 91-132, in Langman de yu gudian de (The romantic and the classic), Shanghai: Xinyue shudian.

Liu, Xiwei [Li Jianwu] (1936), "Leiyu-Cao Yu xiansheng zuo" (Thunderstorm: written by Mr. Cao Yu), 115-126, in Juhua ji (Ruminations), Shanghai: Wenhua shenghuo chubanshe.

Ma, Hui (2006), Minzu beiju yishi yu geti yishu biaoxian (The national tragic consciousness and the individual artistic presentation), Beijing: Minzu chubanshe.

McDougall, Bonnie S., and Kam Louie (1997), The Literature of China in the Twentieth Century, London: Hurst \& Company.

Nobel, Jonathan (2003), "Cao Yu and Thunderstorm", 446-451, in Joshua S. Mostow (ed.), The Columbia Companion to Modern East Asian Literature, New York: Columbia University Press.

Ouyang, Yuqian (1991), "Richu de yanchu" (The staging of Sunrise), 705-706, in 
Tian Benxiang and Hu Shuhe (eds.), Cao Yu yanjiu ziliao, xia (Research material on Cao Yu, Part 2), Beijing: Zhongguo xiju chubanshe.

Qian, Liqun, Wen Rumin and Wu Fuhui (1998), Zhongguo xiandai wenxue sanshi nian (Three decades in modern Chinese literature), Beijing: Beijing daxue chubanshe.

Qian, Zhongshu [Ch'ien, Chung-shu] (1935), "Tragedy in Old Chinese Drama", T'ien Hsia Monthly 1(1): 37-46.

- - (1929), "Xiju gaige zhi lilun yu shiji" (Theory and practice of drama reform), 1-64, in Xiju (Drama), Guangzhou: Guangdong xiju yanjiusuo.

The Editors (1935), "Bianzhe anyu, Leiyu de xiezuo" (Editors' words in "The writing of Thunderstorm"), Zawen 2: 34-36.

Tian, Benxiang (ed.) (1993), Zhongguo xiandai bijiao xiju shi (History of modern Chinese comparative drama), Beijing: Wenhua yishu chubanshe.

Tian, Han (2000), "Baofengyu zhong de Nanjing yitan yipie" (A glance at the art circle of Nanjing in the storm), 282-296, in Tian Han quanji, di shiwu juan, wenlun (Complete works of Tian Han, vol. 15, Literary Criticism), Shijiazhuang: Huashan wenyi chubanshe.

Tong, Weimin (1997), "Leiyu yanjiu liushi nian" (Sixty-years of research on Thunderstorm), Wuhan jiaoyu xueyuan xuebao 16(1): 1-10.

Wang, David Der-wei (2010), "Chinese Literature from 1841 to 1937", 413-564, in Kang-i Sun Chang and Stephen Owen (eds.), The Cambridge History of Chinese Literature, vol. 2, Cambridge: Cambridge University Press.

Wang, Lieyao (2002), Jidujiao wenhua yu Zhongguo xiandai xiju de beiju yishi (Christian culture and the tragic consciousness of modern Chinese drama), Shanghai: Sanlian shudian.

Wang, Weiping (1994), "Jieshou yu bianxing-Cao Yu juzuo de zhuguan zhuiqiu yu guanzhong de keguan jieshou" (Acceptance and variation-The subjective intention and objective reception of Cao Yu's dramas), Shehui kexue zhanxian 1: 243-252.

Xie, Boliang (2014), Zhongguo beiju meixue shi (History of the aesthetics of Chinese tragedy), Shanghai: Shanghai guji chubanshe.

Xiong, Foxi (1933), Xieju yuanli (Principles of play-writing), Shanghai: Zhonghua shuju.

Yue, Daiyun (2015), "Leiyu zhong de renwu xingge" (The characterisation of 
Thunderstorm), 210-216, in Bijiao wenxue yu Zhongguo xiandai wenxue (Comparative literature and modern Chinese literature), Fuzhou: Fujian jiaoyu chubanshe.

Zhang, Geng (1936), "Beiju de fazhan-ping Leiyu" (The development of tragedy-on Thunderstorm), Guangming 1(1): 60-65.

Zhang, Min (1936), Beiju lun (On tragedy), Shanghai: Shangwu yinshuguan.

Zhang, Yaojie (2003), Xiju dashi Cao Yu (Cao Yu the master of drama), Taiyuan: Shanxi jiaoyu chubanshe.

Zhou, Yang (1937), "Lun Leiyu he Richu-bing dui Huang Zhigang xiansheng de piping de piping" (On Thunderstorm and Sunrise-and the critique of criticisms of Mr. Huang Zhigang), Guangming 2(8): 1313-1320.

Zhu, Donglin (2007), Zhongguo xiandai wenxue shi 1917-2000 (History of modern Chinese literature 1917-2000), Beijing: Beijing daxue chubanshe.

Zhu, Guangqian (1987), The Psychology of Tragedy, Hong Kong: Joint Pub. Co.

Zong, Baihua (1934), "Beiju youmo yu rensheng" (The tragic humour and life), Zhongguo wenxue 1 (1): 71-73.

-- (1994), "Yishu xue" (A study on arts), 495-541, in Zong Baihua quanji, di yi juan (Complete works of Zong Baihua, vol. 1), Hefei: Anhui jiaoyu chubanshe.

Tian GU is a Lecturer in Literary and Cultural Studies in the College of Foreign Languages at Nankai University. 